\title{
Monitoring the production of FRP composites: A review of in-line sensing methods
}

\author{
S. Konstantopoulos ${ }^{1 *}$, E. Fauster ${ }^{2}$, R. Schledjewski ${ }^{1,2}$ \\ ${ }^{1}$ Christian Doppler Laboratory for Highly Efficient Composites Processing, Otto Glöckel-Straße 2/I, 8700 Leoben, \\ Austria \\ ${ }^{2}$ Chair of Processing of Composites, Department of Polymer Engineering and Science Montanuniversität, Otto Glöckel- \\ Straße 2/III, 8700 Leoben, Austria
}

Received 28 April 2014; accepted in revised form 8 June 2014

\begin{abstract}
Composites manufacturing is characterized by many degrees of freedom. Different materials, geometries and thermo-dynamical conditions contribute to a behavior that is difficult to predict. Monitoring the running process (in-line monitoring) eliminates the need for prediction; real time data provided by appropriate sensing systems can be used in the direction of process optimization, quality upgrade or material characterization. The aim of the review at hand is to record and discuss the latest progress in the field of in-line composites monitoring with a focus on Fiber Reinforced Polymericbased (FRP) composite structures. Summaries of each sensor's principles of operation, appropriate association with polymer/composite properties detection, brief descriptions of representative studies, a critical overview of implementation aspects and discussion on the upcoming trends, contribute in constructing a complete picture.
\end{abstract}

Keywords: material testing, cure monitoring, flow-front detection

\section{Introduction}

Any composite part is generally characterized by a certain production cost, quality and in-production material behavior. Research areas around each of these topics have been developed in the past years. Naturally, the industry has a high interest in minimizing production costs. In composites manufacturing cost is related to the curing cycle time, adaptivity to batch-to-batch variations, reproducibility, etc. In principle such aspects fall under the field of process optimization. The quality of the final part is highly dependent on the filling and curing processes; filling defects (porosity, dry spots etc.) or cureinduced defects (degradation, under-curing etc.) are considered as a threat to the structural health of the component. Quality upgrade is the area that works in the direction of eliminating defects. Finally, the mechanisms that dominate filling and curing differ depending on the process inputs (materials, geometry and thermo-dynamical conditions). The field that is focused in investigating the material mechanisms with respect to process inputs and theory, is material characterization.

These research areas are distinct yet overlapping; hardly does a study focus in only one of them. Since in-line monitoring serves all three of these territories, it acts as a tool to inter-connect them. The work that has been done in the past in the direction of evaluating the various in-line monitoring techniques is rather limited. In 1991 Huntson [1] made one of the first approaches in evaluating technologies developed in the 80 's to monitor composites manufacturing. In 2003 Mulligan [2] and Summerscales [3] contributed by reviewing mainly advancements of the 90's on in-line monitoring systems for both composites and adhesives. A review of Fon-

\footnotetext{
${ }^{*}$ Corresponding author, e-mail: spiridon.konstantopoulos@unileoben.ac.at (C) BME-PT
} 
Table 1. Detectability chart of sensors monitoring composites manufacturing

\begin{tabular}{|l|l|c|c|c|c|}
\hline \multirow{3}{*}{ Electromagnetic properties } & & $\begin{array}{c}\text { Flow } \\
\text { front }\end{array}$ & $\begin{array}{c}\text { Curing } \\
\text { degree }\end{array}$ & $\begin{array}{c}\text { Void } \\
\text { content }\end{array}$ & Delaminations \\
\hline & Dielectric analysis (DEA) & $\checkmark$ & $\checkmark$ & $\checkmark$ & $\checkmark$ \\
\hline & Direct Current (DC) analysis & $\checkmark$ & $\checkmark$ & & \\
\hline & Electrical time domain reflectometry (ETDR) & $\checkmark$ & $\checkmark$ & & \\
\hline \multirow{2}{*}{ Mechanical properties } & Optical fiber interferometers (OFI) & $\checkmark$ & $\checkmark$ & & \\
\hline & Ultrasonic transducers & $\checkmark$ & $\checkmark$ & $\checkmark$ & $\checkmark$ \\
\hline \multirow{2}{*}{ Optical properties } & Optical fiber refractometers (OFR) & $\checkmark$ & $\checkmark$ & & \\
\hline & Spectrometers & $\checkmark$ & $\checkmark$ & & \\
\hline \multirow{2}{*}{ Thermo-dynamical properties } & Thermometers & $\checkmark$ & $\checkmark$ & & $\checkmark$ \\
\hline & Pressure transducers & $\checkmark$ & & & $\checkmark$ \\
\hline
\end{tabular}

*Only by Infrared (IR) thermography

seca et al. [4] in 2009 focuses on sensors appropriate for neat polymer monitoring in polymerization reactors, not composites manufacturing; yet their work offers valuable input due to the overlapping sensing technologies. Significant input to all chapters of this project were the handbooks of Webster [5] and Fraden [6] that offered concentrated knowledge on measuring and sensing, while the encyclopedic coverage of polymers by Chanda and Roy [7] provided the essential link between sensing and polymer technology.

Technology leaps, commercialization of sensors and production standardization, gave a boost to industrial in-line monitoring implementations. Meanwhile, novel approaches in composites monitoring add continuously to the conquered knowledge. This work aims to serve the need of recording and assessing the advances of the new millennia. A starting point is Table 1 that contains the main sensing methods and their corresponding detection capabilities, categorized by the material property groups. It serves as a roadmap for section 2 that includes summaries of sensing technologies and representative applications in composites manufacturing. More practical aspects of each sensor are discussed in section 3.2 and summarized in Table 2.

\section{Sensing systems}

\subsection{Sensors detecting electromagnetic properties}

\subsubsection{Dielectric analysis (DEA)}

An AC excited circuit generates an electrical field between parallel plates (homogeneous field, Figure 1a) or interdigitated electrodes (fringing electric field or FEF, Figure 1b). The field causes electronic, atomic, dipole polarization and ion migration phenomena to the material within, the last two being

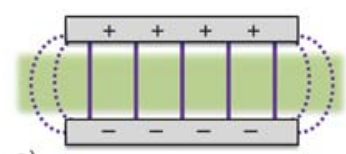

a)

Figure 1. (a) Parallel plate and (b) interdigitated electrodes that create homogeneous and fringing electric fields respectively

the only measurable by DEA. Reorientation of the dipolar molecules (dipole polarization) and migration of ions with the external field frequency $(\omega)$, result in a resistive (energy loss) and capacitive (energy storage) behavior [8]. The complex dielectric permittivity $\left(\varepsilon^{*}\right)$ of a dielectric material is a measure of its resistive and capacitive signature; it is expressed by Equation (1) where the real part of dielectric permittivity $\left(\varepsilon^{\prime}\right)$ is related to the stored energy within the medium and the imaginary or dielectric loss $\left(\varepsilon^{\prime \prime}\right)$ is related to the energy dissipated within the medium. Both the real and imaginary parts can have a dipolar and an ionic component.

The ionic component of the dielectric loss $\left(\varepsilon^{\prime \prime}\right)$ dominates the total dielectric loss in certain frequencies. Furthermore, it is dependent on the ion resistivity or ion viscosity $(\rho)$ (Equation (2)) which is typically the monitoring quantity in polymeric materials due to its strong correlation with the polymeric matrix viscosity $(\eta)$ (Equation (3)) (as viscosity increases, volume loss in the micro-space indicates an increase in disturbance of ionic movement). Based on these dependencies, a sensing system able to monitor the dielectric permittivity can not only give valuable information on the degree of conversion, viscosity and flow front, but also introduce to the user the possibility of frequency selection for characterization on the frequency domain (dielectric spectroscopy). 
$\varepsilon^{*}(\omega)=\varepsilon^{\prime}(\omega)-j \varepsilon^{\prime \prime}(\omega)$

$\varepsilon_{i}^{\prime \prime}=\frac{1}{\rho \omega \varepsilon_{0}}$

$\rho=\frac{6 \pi r \eta}{Z e^{2} N}$

Lee and Kim [9] investigated the dielectric loss behavior of composites produced in an Autoclave. FEF sensors with a constant frequency, recorded the $\varepsilon^{\prime \prime}(T)$ profile. Comparison with DSC (differential scanning calorimetry) showed that the temperature range of the loss curve did not coincide with the temperature range of the curing reaction. The two ranges however, did overlap which enabled the authors to derive geometrically a correlation between the loss, the temperature and the curing degree.

Hegg et al. [10] used parallel plate and FEF sensors to monitor filling within a Resin Transfer Moulding (RTM) tool with a transparent top tool. Although parallel plate sensors showed a linear increase in capacitance as the flow progressed, fringing effects at the sensor edges created a small difference (maximum $5 \mathrm{~mm}$ ) between visual and dielectric data; repeating with FEF sensors eliminated the discrepancy.

Yenilmez and Sozer [11] developed an RTM mould with integrated rectangular electrodes in the cavity walls. The electrodes on the top tool were perpendicular to the ones on the bottom tool resulting this way to fifty measuring points at the cross-linking areas. Single frequency AC excitement resulted in relative permittivity measurements which served finally as the monitoring quantity for both flow (instantaneous increase upon resin arrival) and cure (gradual drop throughout conversion) during manufacturing of polyester/glass and epoxy/glass composites with various fiber volume and catalyst contents.

Kim et al. [12] embedded an FEF sensor between carbon/epoxy prepregs used in composite plate manufacturing by compression moulding. The sensor was excited by a single frequency and the obtained dielectric loss measurements followed closely viscosity changes. Critical process points such as the start and end of cure were determined by the $\varepsilon^{\prime \prime}$ time derivative maximum and minimum values respectively. Kobayashi et al. [13] developed a flexible area sensor with multiple FEF elements. The system was patched on CFRP composites under fabrication aiming to monitor superficial curing gradients and operated in a variety of exciting frequencies. A novel correlation of dielectric measurements with the material state was proposed and used; it is based on the relation between viscosity and the frequency dependence of permittivity. The approach was confirmed by agreement with DSC measurements.

\subsubsection{Direct current (DC) analysis}

A DC electrical circuit specifically designed for resistance measurements is initially open. The Material Under Test (MUT) acts as an electrically conductive medium between the open points. As it closes the circuit, a voltage output proportional to the ion viscosity $(\rho)$ is generated. The mathematical correlation between $\rho$ and the output voltage is not strictly defined as it depends on the electrical circuit design; options vary from a simple voltage divider to a complex circuit with amplification or other enhancements. However, the association between ion viscosity and matrix viscosity discussed for DEA (Equation (3)) applies to DC analysis as well because ion migration remains the dominant mechanism in DC excited polymers [14].

Despite the DC and AC circuits overlapping mathematical descriptions, a significant difference remains; DC sensing offers only time domain analysis in contrast to DEA that can expand in the frequency domain and produce richer measurements. In practice, this disadvantage is counterbalanced by the straightforward and low cost DC based systems. Implementation of DC analysis in composites is typically achieved either by in or out-of-plane electrodes that can measure the resin or composite electrical resistance (Figure 2).
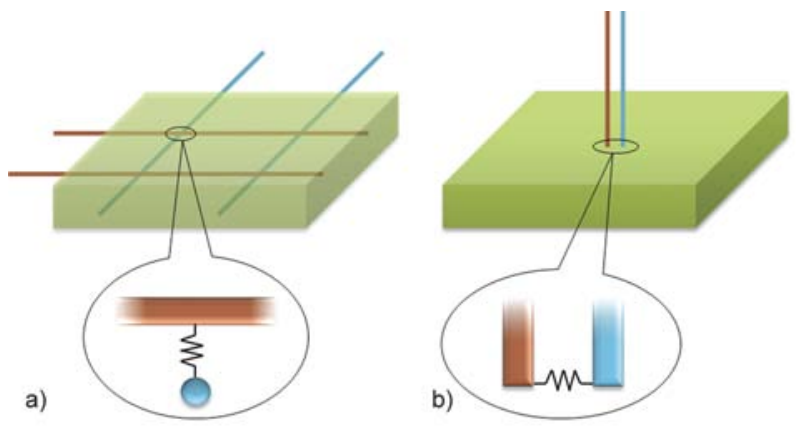

Figure 2. Measurements of the electrical resistance between the exciting (brown) and sensing (blue) electrodes arranged in (a) the in-plane electrode configuration known as the SMARTweave ${ }^{\mathrm{TM}}$ and (b) outof-plane configuration 
Lawrence et al. [15] optimized filling in a complex RTM tool via a multiple gate injection system. Filling simulations were used to predict the dry spot locations around which auxiliary gates were opened and point DC sensors were mounted; they provided real time resin arrival information which was input in a decision making algorithm. A fully automated injection machine with pneumatic grips that open/ closed vents and gates realized the taken decision. Comparison between parts produced by controlled and non-controlled processes, showed that the multiple injection prevented the formation of dry spots. Luthy and Ermanni [16] developed a variation of the SMARTweave ${ }^{\mathrm{TM}}$ method where the sensing and exciting fibrous in-plane electrodes within the preforms are parallel. As the matrix filled the space between them, an electrical signal proportional to the flow front was generated and a model based flow front position was deduced. Difficulties to maintain a constant distance between the fibrous electrodes lead the authors to develop a plate with multiple printed electrodes which however demanded sampling that deteriorated the time domain resolution. Relevant experimentation showed small deviations from the visual detection.

Danisman et al. [17] focused on the development of flow detecting DC sensors and appropriate circuitry for signal conditioning. The prototype with concentric electrodes that operated as a Boolean point sensor was proven to be the most practical for mould integration. To validate, multiple sensors of this type were mounted in an RTM mould and monitored filling experiments. The obtained flow front was verified visually through the transparent top tool.

Garschke et al. [18] investigated the impregnation and cure cycle for Resin Film infusion (RFI) processes. Heating scenarios with different dwell times and heating rates were monitored by a point DC sensor inserted in the vacuum bag. The resistance measurements were correlated to viscosity by a novel model which showed that short dwelling and high rates result in significant cycle reduction but not without increased void formation. However, degassing at elevated temperatures was able to reduce void formation to acceptable levels.

Hsiao [19] derived the thermomechanical behavior of a curing epoxy resin using a single carbon fiber embedded in it. Electrical resistance and the thermal history revealed the $T_{\mathrm{g}}$ corresponding to the abrupt change in the coefficient of thermal expan- sion, the $T_{\mathrm{g}}$ by the storage modulus $\left(E^{\prime}\right)$ onset, and the upper temperature limit for linear $E^{\prime}-T$ relationship. Comparison with the same quantities obtained by dynamic mechanical analysis (DMA) and thermomechanical analysis (TMA) showed good agreement.

\subsubsection{Electric time domain reflectometry (ETDR)}

A high frequency electromagnetic voltage pulse $E_{\mathrm{i}}$ that is driven through a pair of conductors (transmission line), creates electrostatic and magnetic fields around them (Figure 3). The dynamical behavior of material within the field expressed as a discontinuity, causes a reflection waveform $\left(E_{\mathrm{d}}\right)$ that requires finite time to travel back through the lines [20]. The ratio of the incident to the reflection pulse or the electric reflection coefficient $\left(R_{\mathrm{e}}\right)$ is a function of the electrical impedance at the discontinuity location $Z_{\mathrm{d}}$ (Equation (4)). The latter is dependent on both the geometry of the transmission line and the state of the material they are placed in [21].

In composites monitoring, the flow front acts as a discontinuity along the transmission lines that given constant real dielectric permittivity and magnetic permeability $\left(\varepsilon^{\prime}\right.$ and $\left.\mu^{\prime}\right)$ during filling, can be located spatially by measuring the time of flight of the reflected wave (Equation (5)). On the other hand, curing can be detected by changes in the reflection amplitude imposed by the contributions of $\varepsilon^{\prime}$ and $\mu^{\prime}$ in the electrical impedance of the measured discontinuity (Equation (6)). Equations (5) and (6) apply under the assumption that the resistance of the transmission lines and the conductance of the material within the field are negligible (lossless transmission).

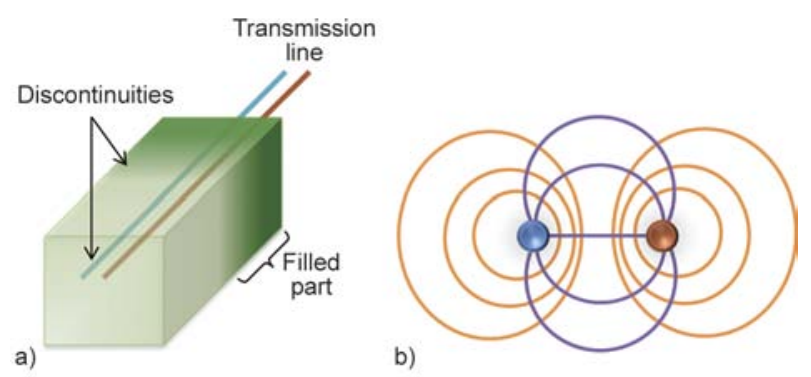

Figure 3. (a) The flow front along the transmission line acts as a reflective interface for the electromagnetic pulse. (b) The electric (purple) and magnetic (orange) field lines around the transmission line electrodes. 


$$
\begin{aligned}
& R_{\mathrm{e}}=\frac{E_{\mathrm{d}}}{E_{\mathrm{i}}}=\frac{Z_{\mathrm{d}}-Z_{0}}{Z_{\mathrm{d}}+Z_{0}} \\
& x=u t=\frac{1}{\sqrt{\varepsilon^{\prime} \mu^{\prime}}} t \\
& Z=K \sqrt{\frac{\mu^{\prime}}{\varepsilon^{\prime}}}
\end{aligned}
$$

Pandey et al. [22] integrated two parallel electrodes on a VaRTM tool as an ETDR transmission line that was used to monitor both filling and curing progression of glass/resin samples. Electrostatic simulations were used to determine the optimal distance between the electrodes with respect to maximizing sensitivity. Flow front detection during filling experiments agreed with visual data while degree of cure measurements of fast and slow curing resin systems were validated by DSC.

Dominauscas et al. [23] developed parallel plate and parallel wire ETDR sensors for flow detection in LCM (liquid composite molding) processes. The parallel wires exhibited higher practicality (flexibility, small size) and performance (higher reflection signal levels due to the wire insulation). Experiments with the wires embedded in the textile in parallel to the flow front showed good agreement with visual data. Multi-flow front detection with a single fiber was demonstrated by placing it perpendicularly to multiple flow fronts.

Dominauscas et al. [24] in a subsequent study developed a transmission line that was partially unshielded in multiple points, allowing for multiple point flow detection. The impedance discontinuity upon resin arrival at each unshielded region creates a reflection that is superimposed in the output signal. The impedance and thus the dielectric distribution is then calculated by inverting a non-uniform transmission line model. Measurements from filling experiments in a mould where a $3.8 \mathrm{~m}$ line with 150 sensing elements was inserted (zigzag arrangement), generally agreed with model-predicted values.

Urabe et al. [25] used carbon fibers to construct an ETDR transmission line that was used to monitor filling and curing of composites. The incident signal was driven through a carbon fiber strand and grounded through a carbon fiber cloth. Although the resin flow front, existence of air, progress and variation of cure were detected successfully, comparison with a metallic line showed that a carbon fiber line produces more obscure results due to the carbon higher electrical resistance.

\subsection{Sensors detecting mechanical properties}

\subsubsection{Optical fiber interferometer (OFI)}

Out of four types of optical fiber interferometers (Fabry-Pérot, Mach-Zehnder, Michelson, Sagnac), Fabry-Pérot are the most attractive for composite applications where multiple point sensing using a single fiber is of the essence. Reflective micro-surfaces along the core of a Fabry-Pérot interferometer cause partial reflection of the light that is travelling through. All reflections contribute to an interference signal characterized by a peak wavelength [26]. Thermal deformation or external strains influence significantly the spacing between the reflective surfaces and their refractive index (Figure 4). As a result environmental strain and temperature cause a shift to the peak wavelength of the reflected signal. The small diameter (typically $125 \mu \mathrm{m}$ ) and immunity to extreme conditions made the OFIs appropriate to insert in composite structures where thermal, cure induced or in-service strains can be measured.

Perhaps the most cited application of OFIs in composites is a special intrinsic Fabry-Pérot interferometer, the Fiber Bragg Grating (FBG) sensor. The reflective micro-surfaces in this case are manufactured by periodical refractive index modulations or gratings on one or more areas along the core of the optical fiber [27]. The reflection peak wavelength or Bragg wavelength $\left(\lambda_{\mathrm{B}}\right)$ is dependent on the grating distance $(\Lambda)$ (Equation (7)). Modifications of $\Lambda$ induced either by changes of the axial strain $\Delta s$ or temperature $\Delta T$ result in a shift of the Bragg peak $\left(\Delta \lambda_{\mathrm{B}}\right)$ (Equation (8)):

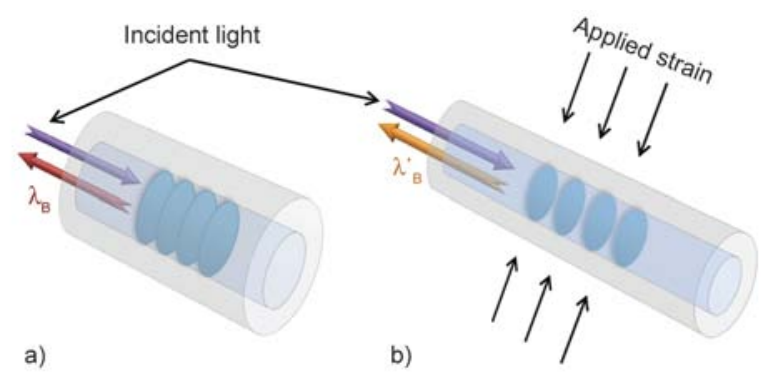

Figure 4. The increase of the grating spacing caused by the applied strain on an FBG sensor (b), results in different Bragg wavelength as compared to strainfree conditions (a) 
$\lambda_{\mathrm{B}}=2 n_{0} \Lambda$

$\Delta \lambda_{\mathrm{B}}=\lambda_{\mathrm{B}}\left(1-p_{\mathrm{e}}\right) \Delta_{\mathrm{s}}+\lambda_{\mathrm{B}}\left(\alpha_{\mathrm{e}}+\xi\right) \Delta T$

Kuang et al. [28] used an FBG sensor to monitor the manufacturing of a novel sandwitch structure (Skin: $300 \mu \mathrm{m}$ aluminium alloy $-300 \mu \mathrm{m}$ fiberglass/ polypropelene, Core: $10 \mathrm{~mm}$ aluminium foam). The part was manufactured by compression moulding during which the embedded sensor recorded the induced strains and detected key process points. Comparison with theoretically expected strains and key points derived by DSC, showed good agreement. Jung and Kang [29] embedded distributed FBGs in braided glass-kevlar/epoxy composites manufactured by RTM. The obtained stress signal was stabilized only after solidification immobilized the sensors. Wavelength peak split was observed which lead to using the full width at half maximum (FWHM) instead. After the stress profile was decoupled from thermal strains, it was compared with post-manufacturing mechanical tests that correlated well with FBG strains.

Khoun et al. [30] detected the strain profile of carbon epoxy composites during an RTM process by use of FBG sensors. The part-tool separation was detected by a difference in the thermal expansion coefficient of different FBGs in the part. The obtained stress values were used for stress simulations development. A model that assumed frictional contact at the part-tool interface agreed best with experimental values.

Archer et al. [31] investigated the usage of extrinsic Fabry-Pérot OFI sensors for cure induced stress monitoring. The sensors were inserted in woven carbon/epoxy composites manufactured with VaRTM and were compared with off-line rheological measurements that recreated the same conditions. A 4 and 10 min difference at the detected gelation and vitrification points respectively was observed.

Tsai et al. [32] examined the potential of cure monitoring by embedded FBGs in carbon/epoxy composites. Vacuum infusion experiments showed that Bragg wavelength shifts and intensity attenuation of the output signal, revealed the conversion progression. During the heating stage the glass transition temperature was detected via a change in the slope of the peak intensity versus wavelength. In the cooling stage peak splitting due to non-uniaxial stresses, was used for residual stresses calculation.

\subsubsection{Ultrasonic transducers}

An ultrasonic wave is a mechanical vibration in the region of $20 \mathrm{kHz}-100 \mathrm{MHz}$, that propagates through small displacements of particles around their equilibrium positions (Figure $5 \mathrm{c}$ ). The relative orientation of the vibration to the wave propagation defines the ultrasonic wave type (Longitudinal, Shear, Rayleigh or Lamb wave). In longitudinal and shear waves the particle vibrations are parallel and perpendicular to the wave propagation respectively. Rayleigh waves have an elliptical orbit with a symmetrical mode whereas Lamb waves have a component perpendicular to the surface. The longitudinal and shear velocities of waves propagating within isotropic material, $\left(c_{1}\right)$ and $\left(c_{\mathrm{s}}\right)$, are given by Equations (9) and (10) respectively [33]. The dependency of the velocities on the density and elastic (Young's) modulus shows that within a curing matrix or composite the 'time of flight' will change as conversion progresses which allows cure monitoring.

The sound wave is also characterized by a loss of energy or attenuation within the media due to friction. Attenuation in composites is considered to be proportional to the impregnation quality on account of the fact that porosity and voids contribute significantly to friction-generating non-elastic responses. A measure of the attenuation is the attenuation coefficient $(a)$, defined as the inverse ratio of change in amplitude to the initial amplitude of the transmitted wave (Equation (11)) [34]. Known configurations of ultrasonic systems are the transmission (Figure 5a) or reflection modes (Figure $5 b$ ). The latter detects wave reflections caused by discontimuities (e.g. material-mould interface) and is considered to produce signals of lower quality. This drawback is counterbalanced by the one sided access which is often of importance in composites manufacturing.
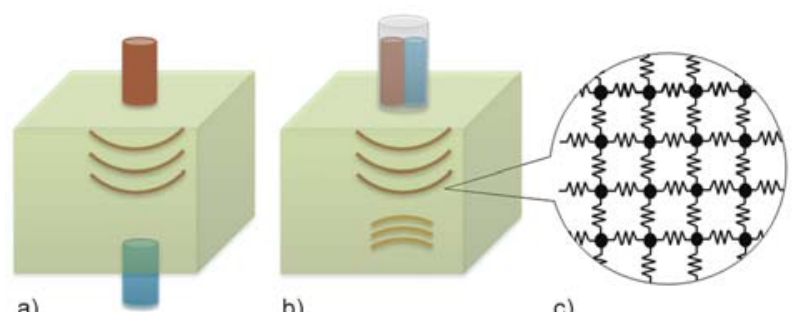

b)

c)

Figure 5. Ultrasonic transmitter (brown) and receiver (blue) arranged in a) transmission and b) reflection mode. The wave propagation can be modeled as the matrix oscillator (c). 


$$
\begin{aligned}
& c_{1}=\sqrt{\frac{E(1-v)}{d(1+v)(1-2 v)}} \\
& c_{\mathrm{s}}=\sqrt{\frac{G}{d}}=\sqrt{\frac{E}{2 d(1+v)}} \\
& a=-\frac{1}{\pi\left(\frac{\Delta A}{A}\right)}
\end{aligned}
$$

Fomitchov et al. [35] developed an optical fiber based ultrasonic system to monitor RTM. A beam produced by the optical fibers reached a graphite layer placed on the top of the preform. Due to rapid thermal expansion it transmitted a pulse through the composite that was detected by an embedded Sagnac OFI. Although the obtained velocity profile revealed the gelation time it did not reveal the end of cure; the velocity continued to increase post curing due to the velocity-temperature dependency.

Schmachtenberg et al. [36] integrated a pitch-catch ultrasonic system in an RTM mould which was used to monitor manufacturing with different reinforcements. Since the sound velocity is affected by the cross-linking process the curing stage was monitored. The amplitude is related to molecular attenuation and consequently to the impregnation quality while both signals could detect the flow front as the wave cannot propagate in dry fiber. Experiments with different pressures/flow rates that were compared with post-curing mechanical tests revealed significant enhancement of mechanical properties with the increase of amplitude maxima.

Visvanathan and Balasubramaniam [37] investigated the potential of flow front detection using ultrasonic waves propagating through a material embedded copper wire. At the wire-flow front interface the wave gets reflected/scattered through mode conversions. The time of flight of the reflected signal is used for spatial location of the flow front (the method can be considered as the equivalent of timedomain reflectometry in mechanical waves). Experimentation revealed that the reflection signal strength is proportional to viscosity, and that the wire is not without length limitations; it must be short enough to keep attenuation at acceptable levels but at the same time long enough to avoid merging with the incident signal.

Pavlopoulou et al. [38] utilized Lamb waves to monitor conversion of glass/epoxy composites. Uncured, semi-cured and cured samples were obtained for testing that involved 2 PZTs in pitch-catch mode. A multi-level signal conditioning procedure was followed: After Ensemble Empirical Mode Decomposition, the optimal Intrinsic Mode Function was used as input to a Hilbert Transform. The resulting weighted frequency versus time function served as the monitoring quantity; it was characterized by a monotonic increase during curing.

Liebers et al. [39] developed a novel ultrasonic sensor for cure monitoring for composite structures that is based on bare piezoceramic elements instead of the typical ultrasonic transducers. It was found that the liability of unstable coupling of the MUT with the transducer was no longer an issue with piezoceramic elements fixed on the mould with an adhesive layer, due to the reduction of the number of reflective interfaces. Experimenting with different piezoceramics with double or single sided access on open mould processes showed higher signal amplitudes and stability.

\subsection{Sensors detecting optical properties \\ 2.3.1. Optical fiber refractometer (OFR)}

As discussed in section 2.2.1, the light travelling through an optical fiber will reflect partially when an interface is reached. Instead of e.g. gratings that the FBG sensor uses, OFRs utilize the optical fiberMUT interface to generate the measured signal which is why direct contact of the optical fiber core with the material is essential.

In case the cladding at a certain point along the fiber is removed (evanescent OFR, Figure 6a), the signal received at the output end has reduced intensity compared to the incident signal [40]; the loss is dependent on the optical reflection coefficient $\left(R_{\mathrm{o}}\right)$. Another approach is to establish contact of the cross sectional surface of one of the ends with the MUT. The other end serves both as an input and output
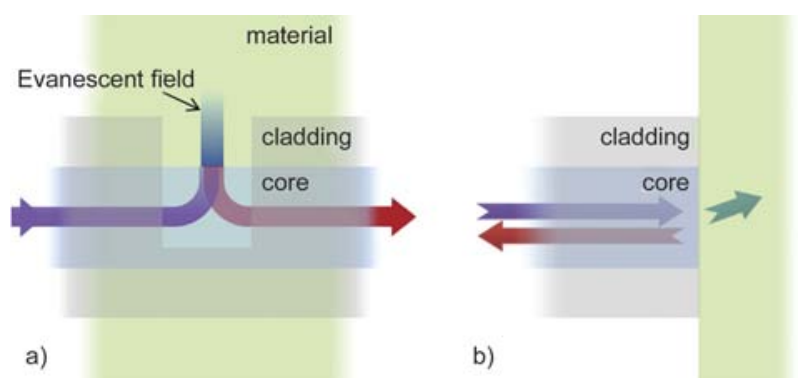

Figure 6. The evanescent (a) and Fresnel (b) optical fiber refractometers. The incident light (purple) is being reflected (red) from axial and cross section interfaces respectively. 
end, the output being a reflection signal from the material-opti- cal fiber interface. The reflection signal in this case abides to Fresnel's law [41] (Fresnel OFR, Figure $6 \mathrm{~b})$ according to which $\left(R_{\mathrm{o}}\right)$ is a function of the refractive indexes of the interfacial materials (Equation (12)). In both cases, cure monitoring is based on the Lorentz-Lorenz law (Equation (13)) which relates the refractive index of a material to its density. As a result, an optical fiber with a bare section inserted in a composite can detect the nature (flow front) or state (curing degree).

$R_{\mathrm{o}}=\left(\frac{n_{1}-n_{2}}{n_{1}+n_{2}}\right)^{2}$

$\frac{n^{2}-1}{n^{2}+1}=\frac{R_{\mathrm{M}}}{M} d$

Wang et al. [42] employed a Fresnel OFR to monitor the production of carbon/epoxy composites by Liquid Resin Infusion. An instant drop of the output signal indicated resin arrival while the curing stage was characterized by a gradual drop followed by a gradual increase. The signal did not cease to increase after the end of cure to shrink-induced density increase.

Lekakou et al. [43] used evanescent OFRs to monitor glass/epoxy composites manufacturing by Resin Infusion under Flexible Tool (RIFT). Upon resin arrival on a short bare region, a sudden intensity drop of the reflected signal was observed and confirmed optically. Experimenting with a long bare region in the flow direction showed an exponential intensity drop as the epoxy covered the core. However, at the point where the loss reaches resolution levels, the accuracy drops. During curing the reflected intensity dropped gradually and stabilized at the end of cure which coincided with the rheological end of cure determination.

Li et al. [44] investigated the potential of cure monitoring of Compression Moulding and Autoclave production using evanescent OFRs. In all cases the output signal followed closely the numerically expected viscosity behavior; a drop (start of cure), a rise (mid-cure) and stabilization (end of cure). Quantification of the drops and rises was not easy due to a sensitivity fluctuation of the sensor that was caused by microbends dependent on the different orientation of the sensing fiber with respect to the reinforcement fibers.
Gupta and Sundaram [45] developed a hybrid FBG evanescent OFR sensor and used it to monitor flow in glass/epoxy specimens manufactured by Vacuum Enhanced Resin Infusion Technology (VERITy). The etched region of the optical fiber was the sensing element and the grated region was out of the part serving as a built-in transducer of the reflected signal to an interference signal. A multi-point flow detection system comprised of consecutive bare and grated regions along a single fiber was developed and experimentally validated; resin arrival was successfully detected on all bare regions.

Buggy et al. [46] employed two Fresnel OFRs operating in different wavelengths to monitor the curing of an epoxy resin. The measured refractive index increased rapidly after an initial decrease, indicating correlation with viscosity. Small deviations were observed between the Fresnel OFR and grating based refractometer measurements mainly due to the coupled strain/temperature effect on the latter.

\subsubsection{Spectrometers}

Generally, a monochromatic or polychromatic light that is directed to a media, causes electron excitement to higher electronic, vibrational or virtual states (Figure 7a). Polychromatic light in the Infrared region excites stable vibrational modes denoted by a frequency loss of the output spectra (Infrared spectroscopy). Monochromatic light typically in the ultraviolet region causes an unstable excitement to a higher electronic and possibly vibrational state. Relaxation back to the original electronic and vibrational state is realized by emitting heat and a photon of characteristic frequency (fluorescence spec-

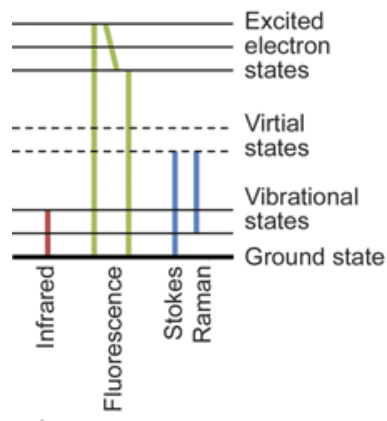

a)

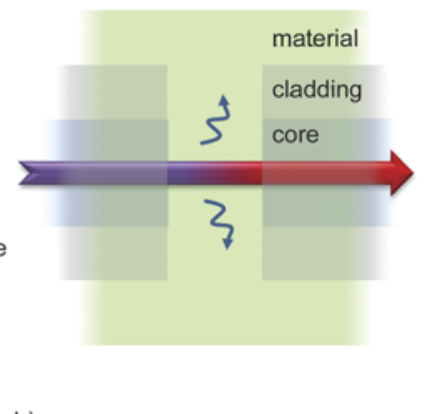

b)
Figure 7. a) Excitation and emission scenarios typical for polymeric materials. b) Optical fiber spectrometer arranged in transmission mode, a configuration appropriate only for absorption (Infrared) and not emission (Fluorescence, Raman) spectra investigations. 
troscopy). Monochromatic light that belongs to the infrared region excites to virtual states, only this time relaxation to higher vibrational modes of the ground state are characterized by photon emission that has a lower energy than the incident light (Raman spectroscopy) [47]. In all three cases, the output emission or absorption spectra characterizes the nature or state of the MUT.

Spectroscopic techniques are unique in that they do not rely on model based correlations with the material state; they detect directly the spectroscopic signature of chemical species. When applied to composites, flow can be detected by the different spectral signature of impregnated versus dry fiber while cure is monitored by detecting wavelength fluctuations or vibrations due to the cross linking process. However, spectroscopic systems are by nature mostly appropriate for laboratory testing. Towards in-line spectroscopy material embedded optical fiber spectrometers (OFS) are mostly employed; they are implemented either by evanescent (Figure 6a) or transmission mode optical fibers (Figure $7 \mathrm{~b}$ ) with the difference that instead of examining the output signal intensity (OFRs), OFSs examine the signal spectra. Other approaches for in-line spectroscopy involve remote optical fiber probes or self-sensing composites.

Wang et al. [48] investigated the potential of using the reinforcing glass fibers of composites as chemical sensors for cure monitoring (self-sensing composites). Experiments involving detection of the evanescent wave infrared spectra of silane-treated glass fibers embedded in epoxy resin, showed good correlation with conventional FTIR spectra for curing temperatures up to $45^{\circ} \mathrm{C}$. However the silica treatment was found to affect the curing kinetics; higher curing rates but lower conversion of epoxy functional groups was observed with the increase of silane concentration.

Mahendran et al. [49] developed transmission mode OFS which were embedded in thermoset resins and used for cure monitoring. Simple fixtures kept the transmitting and receiving end of the optical fiber in position and infrared spectra was acquired periodically throughout conversion at various temperatures. Data from experiments at various temperatures had excellent agreement with conventional transmission spectroscopy.

Dunkers et al. [50] used fluorescence OFS sensors and modified glass fibers to detect filling and cur- ing of composites in a mould with transparent lid. Long period gratings (LPGs) written at the bare regions, prevented specific wavelengths from propagating. Upon resin arrival on the bare regions, the denied wavelengths found an alternative route of propagation thus providing flow front detection. An embedded glass fiber with a fluorescently labeled silane-coupling agent (FLSCA) layer grafted on its surface, emitted a fluorescence peak that shifted as curing progressed. Experimentation showed that flow front detection deteriorated with fiber volume content increase and that there was a dependency of the fluorescence shift on the polarity of the co-silane and the layer thickness.

Wood et al. [51] used near-infrared OFS to monitor composite curing. The poor quality spectrum obtained by a single mode silica fiber, lead the authors to use lead doped and higher refractive index optical fibers aiming to increase the transmitted energy. Although the modified optical fiber clearly indicated a certain wavelength vibration during neat resin curing, it produced noisy results for composites. Further increase of the refractive index of the optical fiber prevented energy escape from the bare region due to complete internal reflection.

Anne et al. [52] employed an IR OFS with a modified core to monitor epoxy resin curing. A vibrating wavelength associated with $\mathrm{C}-\mathrm{O}$ chemical bounds was clearly detected. Significant differences were observed in the curing stage allocation in the time domain between the evolution of the integrated transmission spectra and Principal Component Analysis (PCA). The latter was characterized by the authors as more reliable and reproducible. Finally, the observed absorbency correlated well with model-based predictions.

Cruz and Osswald [53] developed a high precision heating chamber with a silica window that allows remote spectroscopy. Optical fiber probes obtained repeatedly the Raman spectrum of unsaturated polyester (UP) and epoxy resin during isothermal and non-isothermal curing. A clear vibrating peak associated with $\mathrm{C}=\mathrm{C}$ bonds was observed for the UP while the typical vibrating peak expected for epoxy resin suffered from overlapping; an alternative peak associated with the $\mathrm{CH}_{2}$ stress interaction with oxygen was used instead. Although experimentation showed higher curing rates with higher pressures, post curing mechanical tests revealed that the best 
mechanical properties were achieved in non-extreme pressures.

\subsection{Sensors detecting thermodynamic properties}

\subsubsection{Thermometers}

Typical instrumentation for temperature measurements in composite monitoring includes thermocouples and infrared thermometers (either point measurements or infrared thermography) while a growing experimental approach is the use of material embedded optical fiber interferometers (OFIs) with thermal decoupling. Thermocouples exploit the thermoelectric effect; they consist of two metal alloys in contact which produce a voltage proportional to the contact temperature. Infrared thermometers utilize a photosensitive cell to detect from a distance the thermal radiation emitted by a body and transduce it into an electrical signal [54]. OFIs with thermal decoupling infer the temperature by distinguishing the wavelength shift (see section 2.2.1) that is caused from thermal strains alone, in contrast to typical OFIs whose measurement contains both kinematic and thermal strain contributions.

Every operation has a different ideal; indicatively, thermocouples are commonly used due to their standardized production and performance, OFIs when a measurement of rich content (temperature, strain, pressure etc.) is aimed while infrared thermography is ideal for non-intrusive surface temperature gradients detection (e.g. open-mould or large scale processes) or in-depth imperfections (delaminations, dry spots, etc.) detection.

Temperature is of the most influential factors in composites because the polymer cross linking is a thermally activated process. A measure of the thermal effect on polymerization is often expressed by the Williams, Landel, and Ferry (WLF) dependency of viscosity on temperature (Equation (14)). Heat induced variations of viscosity define the conversion rhythm and can play a role in filling quality. However, the heating system defines the heat that reaches the material only to a certain degree; poor heating regulation, the heat capacity/thermal conductivity of the composite and the exothermic heat produced by thermoset matrices are contributing factors that need to be accounted for. Temperature monitoring aims to include all these factors in optimizing the part heating.

$$
\log \left(\frac{\eta}{\eta_{\mathrm{T}_{\mathrm{g}}}}\right)=\frac{-17.44\left(T-T_{\mathrm{g}}\right)}{51.6+\left(T-T_{\mathrm{g}}\right)}
$$

Hsiao et al. [55] used distributed thermocouples in the interior of a polyester/glass fiber composite to monitor curing during a VaRTM process. The measurements were used to validate a model-based fitting technique consisting of a genetic algorithm optimizer and a one-dimensional cure simulator which aimed to adjust the curing kinetics on actual LCM conditions.

Tuncol et al. [56] used thermocouples to monitor the flow front propagation of an RTM process. Given a mould-resin temperature difference, the flow was detected reasonably fast when the mould was made of acrylic but delay was observed when an aluminium mould was used, attributed to the higher thermal diffusivity of metal. The authors advise against the usage of thermocouples for flow front detection in metallic moulds, while in non-metallic they must be used with caution.

Marin et al. [57] wrote a long period grating (LPG) and a Bragg grating (FBG) on the same fiber zone. The superimposed gratings result in a good discrimination of thermal and kinematic strains. To verify the accuracy in temperature detection, the sensor was used in a liquid resin infusion process for a glass/epoxy specimen. The temperature recorded during curing deviated negligibly from parallel thermocouple measurements.

Yoon et al. [58] wrote FBGs in two optical fibers with different dopants in the core and spliced them so that the FBGs were adjacent. The resulting sensing element discriminates efficiently thermal from kinematic strains. This ability was tested by embedding the sensor in a Kevlar/Epoxy composite with shape memory alloy (SMA) micro-wires. Very good agreement with comparative thermocouple measurements during curing was observed. Post curing activation of the SMA caused contractions which were measured by the sensor and were found to agree well with theoretically expected values.

Cuevas et al. [59] utilized thermal imaging to detect artificial defects as deep as six layers from the surface of both cured and uncured composite specimens. Better results were obtained with halogen lamb excitation and frequencies below $100 \mathrm{~Hz}$, while signal conditioning improved detection further. Wang et al. [42] distributed micro-thermocouples in the interior of carbon preforms in order to monitor 
through thickness and in-plane flow movement of epoxy resin during the LRI process. An increase in temperature upon the pre-heated resin arrival in every point allowed the thermocouples to characterize the filling behavior for experiments with different heating systems. The experimental data were in agreement with simulations concerning the flow movement. However, significant deviation between the actual and predicted filling time indicated actual temperature variations that were not considered in the simulation.

\subsubsection{Pressure transducers}

Typically pressure sensors exploit the piezoresistive effect; a change in the electrical resistance of the sensing element upon pressure application. Alternatively, piezoelectric sensors exploit the ability of crystals to produce a flow of electric charge when elastically deformed. In either case, the sensing element is installed in a shell where the pressure under measurement and a reference pressure can be isolated. Depending on the reference pressure (vacuum, ambient or arbitary) the sensor results in different types of pressure measurements (absolute, gage or differential respectively) [5].

The significance of pressure in composites manufacturing lies on that it has a major influence on filling, a crucial stage where flow propagation discrepancies bound to affect the overall part quality can occur. Moreover due to thermodynamics it affects the curing reaction inversely to temperature. For these reasons studies focused mostly on filling behavior and filling simulations rely on pressure sensors in their experimental configurations.

Di Fratta et al. [60] proposed the detection of the flow front during an LCM process by use of pressure sensing combined with numerical modelling of the pressure distribution. The model can estimate the flow front in real-time with only a few pressures as input. Validation experiments of various filling scenarios in a mould with a transparent top tool and 3 pressure sensors showed good agreement with visual data.

Govignon et al. [61] developed a monitoring system for Resin Infusion capable of capturing dynamically the fiber volume fraction via a stereophotogrammetry unit. Complementary distributed pressure sensors correlated the pressure gradient along the preform with thickness changes and provided additional data for comparison with simulations.
Xin et al. [62] developed a high accuracy pressure measurement system for zero-bleeding Autoclave processes. Appropriate experimentation in Autoclave revealed a uniform pressure distribution along through-thickness and in plane directions. The pressure profile was proven to conform to the pistonspring model and to be independent of the vacuum condition while it is strongly influenced by the prepreg fiber volume fraction and compaction properties.

Simacek et al. [63] investigated the post filling residual flows in LCM processes with compliant tool. A previously proposed model was compared with experiments where pressure and thickness at various locations during the post filling stage are examined. There was good qualitative correlation between the model and the experimental data. Quantitative discrepancies have been observed in the prediction of the final part thickness, related to poor control, insufficient material characterization and the natural variability of the process.

Kobayashi et al. [64] modeled pressure fluctuations during compression moulding to predict the resin impregnation with micro-braided yarns. For validation, a mould including a pressure sensor was developed and tested in the fabrication of FRP composites. The measured pressure history was used for the analytical prediction which was confirmed by practice.

\section{Discussion}

\subsection{Emerging trends and technologies}

Undoubtedly, each and every publication takes steps towards uncharted territory, while progress in commercialization/standardization of sensing systems can be observed. Having said these general remarks, the authors comment on the overall progress and new directions of in-line monitoring in composite production (as compared to a decade ago), as follows:

- Structural health monitoring and smart composites $^{*}[65]$ motivated large volume of work on material embedded optical fibers. As a result, optical fibers have found their way in measuring in-line almost all kinds of material properties (electrical properties is the only exception due to the fact

\footnotetext{
*Composites that respond to environmental impacts towards preserving their safety without substantially changing their original functionality.
} 
that optical fibers are electrically inert): Ultrasonic wave propagation, refractive index, stress, temperature, energy absorption today have all been monitored in multiple research studies with optical fiber technology.

- Material invasive sensors (optical fibers, electrodes etc.) can be a threat to structural health. Besides the typical non-invasive approach of contact sensors (DEA, Ultrasonics etc.), a clear tendency towards self-sensing composites ${ }^{*}[66]$ is emerging. The most common self-sensing approach is the usage of the reinforcing carbon fiber as electrodes for electrical property sensing. Similar usage of glass fibers in optical property sensing is another possibility. Although significant work has already been done in damage detection with self-sensing [67-69], it is the belief of the authors that the first steps in in-line monitoring via self-sensing composites are being made at the moment by studies such as $[19,48,50,70]$.

- Electrical time-domain reflectometry (ETDR), a method based on measuring the time of flight of electrical signals, was implemented in composites for the first time. The method shows potential in in-line monitoring [22-24], damage detection [71-73] and self-sensing [73, 25]. Moreover, it is the only method able to detect both electric and magnetic properties. Although conventional composites are not magnetic, magnetic microwire inserts that magnetize the composite, make magnetic measurements meaningful. Research interest is attracted to polymeric composites with embedded microwires [74-77] because they are considered as a tool to develop multifunctional composites $^{* *}[78,79]$.

\subsection{Implementation assessment of sensing systems}

The problem of selecting the appropriate sensing technique for a given application is a multi-disciplinary one. Luckily technology leaps have eliminated factors that needed consideration in the past; indeed all commercially available sensors addressing composites manufacturing share a minimum of specifications related to their endurance in harsh environ-

${ }^{*}$ Composites that exploit some of the involved materials as sensing elements.

${ }^{* *}$ Composites with multiple functions that are enabled by the constitutive materials. ments, sensitivity, accuracy and digital connectivity with variations rather insignificant towards composite manufacturing needs. Nevertheless attributes related to the measurement content and sensor positioning still remain and will be discussed in this section.

Perhaps the most significant attribute of a sensor is the information it produces. For the objectives discussed in the introduction, at least two transitions have to be made from what is actually measured; the first transition is from the measured quantity to a material property (e.g. a thermocouple is actually measuring a voltage difference which is used to infer the material temperature). The second transition is from the material property to another material property or a process property (e.g. the temperature of the material can be used to infer the stage of the curing process). The initially measured quantity (e.g. voltage in case of thermocouples) defines the sensitivity and accuracy of the inferred properties; it is therefore significant to investigate ways to improve the initial measurement qualitatively. However such a topic falls under the area of sensor development and will not be examined in the current study. On the other hand, material properties (electromagnetic, mechanical, optical, thermodynamic) and process properties (flow front, degree of cure, defects) will be briefly referred to, in order to know what to expect ultimately from each sensing technique (Table 2/rows 1-5).

As discussed in section 3.1, the needs for throughlife and non-invasive monitoring of composite structures, have directed attention around the areas of smart and self-sensing composites respectively. Indicatively, optical fibers are of the most promising sensing method that can contribute to smart composites. But not the only; resistance measurements of the carbon reinforcement (both in or post production) is another example. The same method can of course be categorized as self-sensing since the reinforcement is part of the material. Alternatively, light propagation within common glass fibers can be used to derive intensity modulation or even spectra, both of which have been proven to monitor cure. The attributes 'smart' and 'self-sensing' (Table 2/ rows 6 and 7) inform the reader of the potential of each sensor towards these two directions.

The position of the sensor with respect to the MUT (Table 2/row 8) is of great importance for two reasons: It defines the invasiveness and the reusability; 
Table 2. Typical implementation attributes of contemporary in-line FRP monitoring techniques

\begin{tabular}{|c|c|c|c|c|c|c|}
\hline & DEA & Out-of-plane DC & In-plane DC & ETDR & OFI & $\begin{array}{l}\text { Ultrasonic } \\
\text { transducer }\end{array}$ \\
\hline Material property & $\begin{array}{c}\text { Complex } \\
\text { dielectric } \\
\text { permittivity }\end{array}$ & \multicolumn{2}{|c|}{ Electrical resistance } & $\begin{array}{l}\text { Real permittivity, } \\
\text { magnetic } \\
\text { permeability }\end{array}$ & $\begin{array}{l}\text { Strain, } \\
\text { temperature }\end{array}$ & $\begin{array}{l}\text { Micro-mechanical } \\
\text { impedance }\end{array}$ \\
\hline Flow Front & $\checkmark$ & $\checkmark$ & $\checkmark$ & $\checkmark$ & $\checkmark$ & $\checkmark$ \\
\hline Curing degree & $\checkmark$ & $\checkmark$ & $\checkmark$ & $\checkmark$ & $\checkmark$ & $\checkmark$ \\
\hline Void content & $\checkmark$ & & & & & $\checkmark$ \\
\hline Delaminations & $\checkmark$ & & & & & $\checkmark$ \\
\hline Smart & & & $\checkmark$ & & $\checkmark$ & \\
\hline Self-Sensing & & & $\checkmark$ & $\checkmark$ & & \\
\hline $\begin{array}{l}\text { Position relative to } \\
\text { the MUT }\end{array}$ & $\begin{array}{l}\text { Contact/ } \\
\text { Embedded }\end{array}$ & $\begin{array}{c}\text { Contact/ } \\
\text { Embedded }\end{array}$ & Embedded & $\begin{array}{c}\text { Contact/ } \\
\text { Embedded }\end{array}$ & Embedded & Contact \\
\hline Spatial allocation & $\begin{array}{l}\text { 3-D point/ } \\
\text { 3-D areal }\end{array}$ & point & point/lineal/areal & $\begin{array}{l}\text { 3-D lineal/ } \\
\text { 3-D areal }\end{array}$ & point & 3-D point \\
\hline $\begin{array}{l}\text { Post manufacturing } \\
\text { usage }\end{array}$ & - & - & SHM & SHM & SHM & NDE \\
\hline $\begin{array}{l}\text { Industrial } \\
\text { Applicability }\end{array}$ & $\checkmark$ & $\checkmark$ & & & & $\checkmark$ \\
\hline $\begin{array}{l}\text { Practical } \\
\text { limitations }\end{array}$ & \multicolumn{2}{|c|}{$\begin{array}{l}\text { Require electrical isolation from } \\
\text { carbon fibers }\end{array}$} & \multicolumn{2}{|c|}{$\begin{array}{l}\text { Only for glass fiber reinforcements, } \\
\text { laborious installation }\end{array}$} & $\begin{array}{l}\text { Fragility, } \\
\text { laborious } \\
\text { installation }\end{array}$ & $\begin{array}{l}\text { Requires high } \\
\text { fixation pressure }\end{array}$ \\
\hline
\end{tabular}

\begin{tabular}{|c|c|c|c|c|c|}
\hline & OFR & Spectrometer & Thermo-couple & IR thermo- graphy & Pressure transducer \\
\hline Material property & Refractive index & $\begin{array}{c}\text { Absorption/ } \\
\text { emission spectra }\end{array}$ & Temperature & $\begin{array}{l}\text { Superficial } \\
\text { temperature }\end{array}$ & Pressure \\
\hline Flow Front & $\checkmark$ & $\checkmark$ & $\checkmark$ & & $\checkmark$ \\
\hline Curing degree & $\checkmark$ & $\checkmark$ & $\checkmark$ & $\checkmark$ & \\
\hline \multicolumn{6}{|l|}{ Void content } \\
\hline Delaminations & & & & $\checkmark$ & \\
\hline Smart & & & & & $\checkmark$ \\
\hline Self-Sensing & & $\checkmark$ & & & \\
\hline $\begin{array}{l}\text { Position relative to } \\
\text { the MUT }\end{array}$ & Embedded & Embedded & $\begin{array}{c}\text { Contact/ } \\
\text { Embedded }\end{array}$ & Remote & Contact \\
\hline Spatial allocation & point/lineal & point & point & areal & point \\
\hline $\begin{array}{l}\text { Post manufacturing } \\
\text { usage }\end{array}$ & - & - & - & NDE & - \\
\hline $\begin{array}{l}\text { Industrial } \\
\text { Applicability }\end{array}$ & & & $\checkmark$ & $\checkmark$ & $\checkmark$ \\
\hline Practical limitations & $\begin{array}{l}\text { Fragility, laborious } \\
\text { installation }\end{array}$ & $\begin{array}{l}\text { A through beam } \\
\text { window required } \\
\text { (remote } \\
\text { spectrometers), } \\
\text { fragility (OFS), } \\
\text { laborious installation }\end{array}$ & - & $\begin{array}{l}\text { Requires open or } \\
\text { transparent } \\
\text { moulding, high } \\
\text { parasitic content }\end{array}$ & - \\
\hline
\end{tabular}

if the sensor is material embedded it can have a negative structural effect on the composite and it is considered disposable as in most cases extracting it from the part is impossible. Solutions that only require contact are only invasive to the reactor (e.g. mould) and not to the material, thus exhibit higher reusability. Remote methods are of course noninvasive to either material or reactor and since they do not suffer from contact friction effects or cleaning-induced damages, are even more reusable. It must be noted, however, that remote methods usually require optical contact with the MUT therefore their usage is limited to open or transparent mould processes.

The spatial allocation of the measurement (Table 2/ row 9) is to give a feeling to the reader of the geometry of the space that is actually being measured with each system. When this is a localized planar space (e.g. in case of one sided access systems it is the plane defined by the exciting and sensing elements), the measurement is characterized as point measurement. When the space is expanded (not localized) on the same plane in a line or area, the measurement can be distinguished correspondingly to lineal meas- 
urement or areal measurement. Measurements that include information from out-of-plane space (e.g. DEA) will be referred to as 3-dimentional (3-D). Some methods offer various possibilities in that regard. For instance, when the electrodes of an inplane DC system are placed perpendicularly to each other (SMARTweaveTM), point measurements are taken from the cross-linking locations. When the electrodes are parallel with a small or large distance between them, lineal or areal measurements are produced respectively.

Post-manufacturing and in-line testing are overlapping territories. The potential of post manufacturing usage of an in-line sensing technique (Table 2/row 10 ) is mainly addressing the areas of Non-Destructive Evaluation (NDE) [80] and Structural Health Monitoring (SHM) [81]. Such potential is intriguing in that a single system would cover a larger portion of the life-span of a composite part. Perhaps the most controversial example in that context are the OFIs that can monitor the strains applied on a part both in-production and in-service. The drawback in this case is the lack of reliable assessment of the effect of the embedded optical fibers on the structural health of the part. It must be noted that this drawback does not apply to all methods with postmanufacturing potential (e.g. Ultrasonics are not material embedded which is why non-destructive ultrasonic testing is an industrially standardized process).

Typically, all sensing methods can be used in a laboratory but mostly the ones that are not material intrusive are attracted to industry. Indeed, the existing protocol of standardized industrial processes excludes anything that compromises the structural integrity of a part (e.g. a material embedded sensor) while a second argument against them is the intensive labor and high costs involved in embedding. As a result, material embedded solutions find only laboratory applications; the current trend in industrial moulds are sensors that require only superficial contact with the material. The extreme mould conditions have triggered the development of a new generation of sensor probes appropriate for mounting in moulds; their shells protect from the common mould temperatures and pressures. The probes are connected to remote measuring units that contain the less tolerant components of the measuring system (e.g. electronics and circuitry). Commercial probes of the kind can be found for thermocouples, pressure transducers, DEA, DC, Ultrasonic or even Spectroscopy. IR thermography can also be used industrially but is limited to visible operations. The potential of industrial usage is given by (Table $2 /$ row 11).

Each sensing approach has limitations of different nature, depending on the principle of operation. Focusing more on practical operational restrictions, one can comment for example that sensors monitoring electrical properties (DEA, DC etc.) either cannot be used with carbon (conductive) fibers, or that they need additional isolation from them. Optical fiber-based methods (OFI, OFR, OFS) need laborious installation within the composite specimen while they are highly fragile which means that the probability of sensor destruction is higher than usual and needs to be taken into account for both cost and efficiency reasons. Another example is the high fixation pressure required by ultrasonic transducers in order to achieve acoustic coupling. Given that during conversion the pressure of the probe on the material varies (e.g. due to material shrinkage), a screw fixation is not enough; alternative means of fixation pressure (e.g. spring) must be used. The major known practical limitations of each method are briefly referred to in (Table 2 /row 12 ).

\section{Conclusions}

The latest advances on in-line monitoring of FRP composites were summarized in the current review. The theoretical grounds of optical fiber, electrical or sound wave-based technologies were discussed, with respect to their interpretation to electromagnetic, mechanical, optical or thermodynamic material properties. Selected publications of the last fourteen years in composites in-line sensing depict the interest in smart, self-sensing and multifunctional composite structures. An evaluation with respect to practical implementation aspects summarizes the overall abilities and drawbacks of each system within an actual setup.

$\begin{array}{ll}\text { Nomenclature } \\ \varepsilon^{*} \quad \text { Complex dielectric permittivity } \\ \varepsilon^{\prime} \quad \text { Real dielectric permittivity } \\ \varepsilon^{\prime \prime} \quad \text { Dielectric loss } \\ \varepsilon_{\mathrm{i}}{ }^{\prime \prime} & \text { Ionic component of the dielectric loss } \\ \varepsilon_{0} & \text { Air replacement permittivity } \\ \Lambda & \text { Grating spacing } \\ \lambda_{\mathrm{B}} & \text { Bragg wavelength } \\ \mu & \text { Magnetic permeability }\end{array}$


E Young's modulus

$E_{\mathrm{i}} \quad$ Electromagnetic voltage pulse

$E_{\mathrm{d}} \quad$ Electromagnetic reflection waveform

$e \quad$ Electron charge

$G \quad$ Shear modulus

$K$ Geometric constant of the transmission line

$M \quad$ Molar mass

$N \quad$ Concentration of ionic species

$n \quad$ Refractive index

$n_{0} \quad$ Core refractive index

$p_{\mathrm{e}} \quad$ Photo-elastic constant

$R_{\mathrm{M}}$ Molar refractivity

$R_{\mathrm{e}} \quad$ Electric reflection coefficient

$R_{\mathrm{O}} \quad$ Optical reflection coefficient

$r \quad$ Average radius of ionic species

$s \quad$ Axial strain

$T$ Temperature

$T_{\mathrm{g}} \quad$ Glass transition temperature

$v$ Poisson's ratio

$v \quad$ Poisson's ratio

$Z \quad$ Average number of electric charges of ionic species

\section{Acknowledgements}

The authors kindly acknowledge the financial support provided by the Bundesministerium für Wirtschaft, Familie und Jugend.

\section{References}

[1] Huntson D.: Assessment of the state-of-the-art for process monitoring sensors for polymer composites. U.S. Department of Commerce, National Institute of Standards and Technology, Materials Science and Engineering Laboratory, Washington (1991).

[2] Mulligan D. R.: Cure monitoring for composites and adhesives. Rapra, Shawbury (2003).

[3] Summerscales J.: In-process monitoring for control of closed-mold techniques for the manufacture of thermosetting matrix composites. in 'Advanced polymeric materials'. (eds.: Shonaike G. O., Advani S. G.) CRC Press, Boca Raton, 55-97 (2003).

[4] Fonseca G. E., Dubé M. A., Penlidis A.: A critical overview of sensors for monitoring polymerizations. Macromolecular Reaction Engineering, 3, 327-373 (2009).

DOI: $10.1002 / \mathrm{mren} .200900024$
[5] Webster J. G.: The measurement, instrumentation, and sensors handbook. CRC Press, Boca Raton (1999).

[6] Fraden J.: Handbook of modern sensors. AIP Press/Springer, New York (2004).

[7] Chanda M., Roy S. K.: Plastics technology handbook. CRC Press, Boca Raton (2007).

[8] Vassilikou-Dova A., Kalogeras I. M.: Dielectric analysis (DEA). in 'Thermal analysis of polymers, fundamentals and applications'. (eds.: Menczel J. D., Prime R. B.) Wiley, Hoboken, 497-613 (2009). DOI: $10.1002 / 9780470423837 . c h 6$

[9] Lee D. G., Kim H. G.: Non-isothermal in situ dielectric cure monitoring for thermosetting matrix composites. Journal of Composite Materials, 38, 977-993 (2004). DOI: $10.1177 / 0021998304040563$

[10] Hegg M. C., Ogale A., Mescher A., Mamishev A., Minaie B.: Remote monitoring of resin transfer molding processes by distributed dielectric sensors. Journal of Composite Materials, 39, 1519-1539 (2005). DOI: $10.1177 / 0021998305051083$

[11] Yenilmez B., Murat Sozer E.: A grid of dielectric sensors to monitor mold filling and resin cure in resin transfer molding. Composites Part A: Applied Science and Manufacturing, 40, 476-489 (2009).

DOI: $10.1016 /$ j.compositesa.2009.01.014

[12] Kim S. S., Murayama H., Kageyama K., Uzawa K., Kanai M.: Study on the curing process for carbon/ epoxy composites to reduce thermal residual stress. Composites Part A: Applied Science and Manufacturing, 43, 1197-1202 (2012).

DOI: 10.1016/j.compositesa.2012.02.023

[13] Kobayashi S., Matsuzaki R., Todoroki A.: Multipoint cure monitoring of CFRP laminates using a flexible matrix sensor. Composites Science and Technology, 69, 378-384 (2009).

DOI: $10.1016 /$ j.compscitech.2008.10.029

[14] Blythe A. R., Bloor D.: Electrical properties of polymers. Cambridge University Press, Cambridge, New York (2005).

[15] Lawrence J. M., Hsiao K-T., Don R. C., Simacek P., Estrada G., Sozer E., Stadtfeld H. C., Advani S. G.: An approach to couple mold design and on-line control to manufacture complex composite parts by resin transfer molding. Composites Part A: Applied Science and Manufacturing, 33, 981-990 (2002).

DOI: $10.1016 / \mathrm{S} 1359-835 \mathrm{X}(02) 00043-\mathrm{X}$

[16] Luthy T., Ermanni P.: Flow monitoring in liquid composite molding based on linear direct current sensing technique. Polymer Composites, 24, 249-262 (2003). DOI: $10.1002 / p c .10026$

[17] Danisman M., Tuncol G., Kaynar A., Sozer E. M.: Monitoring of resin flow in the resin transfer molding (RTM) process using point-voltage sensors. Composites Science and Technology, 67, 367-379 (2007). DOI: $10.1016 /$ j.compscitech.2006.09.011 
[18] Garschke C., Weimer C., Parlevliet P. P., Fox B. L.: Out-of-autoclave cure cycle study of a resin film infusion process using in situ process monitoring. Composites Part A: Applied Science and Manufacturing, 43, 935-944 (2012).

DOI: $10.1016 /$ j.compositesa.2012.01.003

[19] Hsiao K-T.: Embedded single carbon fibre to sense the thermomechanical behavior of an epoxy during the cure process. Composites Part A: Applied Science and Manufacturing, 46, 117-121 (2013). DOI: 10.1016/j.compositesa.2012.11.007

[20] Robinson D. A., Jones S. B., Wraith J. M., Or D., Friedman S. P.: A review of advances in dielectric and electrical conductivity measurement in soils using time domain reflectometry. Vadose Zone Journal, 2, 444475 (2003). DOI: $10.2136 /$ vzj2003.4440

[21] Agilent Technologies: Time domain reflectometry theory. Application note (2014).

[22] Pandey G., Deffor H., Thostenson E. T., Heider D.: Smart tooling with integrated time domain reflectometry sensing line for non-invasive flow and cure monitoring during composites manufacturing. Composites Part A: Applied Science and Manufacturing, 47, 102108 (2013).

DOI: $10.1016 /$ j.compositesa.2012.11.017

[23] Dominauskas A., Heider D., Gillespie J. W.: Electric time-domain reflectometry sensor for online flow sensing in liquid composite molding processing. Composites Part A: Applied Science and Manufacturing, 34, 67-74 (2003).

DOI: $10.1016 / \mathrm{S} 1359-835 \mathrm{X}(02) 00232-4$

[24] Dominauskas A., Heider D., Gillespie J. W.: Electric time-domain reflectometry distributed flow sensor. Composites Part A: Applied Science and Manufacturing, 38, 138-146 (2007).

DOI: $10.1016 /$ j.compositesa.2006.01.019

[25] Urabe K., Okabe T., Tsuda H.: Monitoring of resin flow and cure with an electromagnetic wave transmission line using carbon fiber as conductive elements. Composites Science and Technology, 62, 791-797 (2002).

DOI: 10.1016/S0266-3538(02)00047-7

[26] Błażejewski W., Gąsior P., Kaleta J.: Application of optical fibre sensors to measuring the mechanical properties of composite materials and structures. in 'Advances in composite materials - Ecodesign and analysis'. (ed.: Attaf B.) InTech, Rijeka, 221-246 (2011). DOI: $10.5772 / 13954$

[27] Lee B. H., Kim Y. H., Park K. S., Eom J. B., Kim M. J., Rho B. S., Choi H. Y.: Interferometric fiber optic sensors. Sensors, 12, 2467-2486 (2012).

DOI: $10.3390 / \mathrm{s} 120302467$
[28] Kuang K. S. C., Zhiang L., Cantwell W. J., Bennion I.: Process monitoring of aluminum-foam sandwich structures based on thermoplastic fibre-metal laminates using fibre Bragg gratings. Composites Science and Technology, 65, 669-676 (2005). DOI: $10.1016 /$ j.compscitech.2004.09.005

[29] Jung K., Kang T. J.: Cure monitoring and internal strain measurement of 3-d hybrid braided composites using fiber bragg grating sensor. Journal of Composite Materials, 41, 1499-1519 (2007). DOI: $10.1177 / 0021998306068088$

[30] Khoun L., de Oliveira R. D., Michaud V., Hubert P.: Investigation of process-induced strains development by fibre Bragg grating sensors in resin transfer moulded composites. Composites Part A: Applied Science and Manufacturing, 42, 274-282 (2011). DOI: $10.1016 /$ j.compositesa.2010.11.013

[31] Archer E., Broderick J., McIlhagger A. T.: Internal strain measurement and cure monitoring of 3D angle interlock woven carbon fibre composites. Composites Part B: Engineering, 56, 424-430 (2014).

DOI: $10.1016 /$ j.compositesb.2013.08.067

[32] Tsai L., Cheng T-C., Lin C-L., Chiang C-C., Meyendorf N. G., Peters K. J., Ecke W.: Application of the embedded optical fiber Bragg grating sensors in curing monitoring of Gr/epoxy laminated composites. in 'Proceeding of the $16^{\text {th }}$ International Symposium on: Smart Structures and Materials and Nondestructive Evaluation and Health Monitoring, San Diego, USA' Vol 7293, 7-8 (2009).

DOI: $10.1117 / 12.817520$

[33] Nakamura K.: Ultrasonic transducers. Woodhead Publishing, Cambridge (2012).

[34] Lempriere B. M.: Ultrasound and elastic waves. Academic Press, Amsterdam (2002).

[35] Fomitchov P. A., Kim Y. K., Kromine A. K., Krishnaswamy S.: Laser ultrasonic array system for real-time cure monitoring of polymer-matrix composites. Journal of Composite Materials, 36, 1889-1901 (2002). DOI: $10.1177 / 0021998302036015245$

[36] Schmachtenberg E., Schulte zur Heide J., Töpker J.: Application of ultrasonics for the process control of resin transfer moulding (RTM). Polymer Testing, 24, 330338 (2005). DOI: 10.1016/j.polymertesting.2004.11.002

[37] Visvanathan K., Balasubramaniam K.: Ultrasonic torsional guided wave sensor for flow front monitoring inside molds. Review of Scientific Instruments, 78, 015110/1-015110/8 (2007).

DOI: $10.1063 / 1.2432258$

[38] Pavlopoulou S., Soutis C., Staszewski W. J.: Cure monitoring through time-frequency analysis of guided ultrasonic waves. Plastics, Rubber and Composites, 41, 180-186 (2012). DOI: 10.1179/1743289811Y.0000000052 
[39] Liebers N., Raddatz F., Schadow F.: Effective and flexible ultrasound sensors for cure monitoring for industrial composite production. in 'Proceedings of Deutscher Luft- und Raumfahrtkongress (DGLR). Berlin, Germany', 281405/1-281405/6 (2012).

[40] Yu F., Yin S.: Fiber optic sensors. Marcel Dekker (2002).

[41] Sharma K. K.: Optics: Principles and applications. Academic Press, Amsterdam (2006).

[42] Wang P., Molimard J., Drapier S., Vautrin A., Minni J. C.: Monitoring the resin infusion manufacturing process under industrial environment using distributed sensors. Journal of Composite Materials, 46, 691-706 (2012).

DOI: $10.1177 / 0021998311410479$

[43] Lekakou C., Cook S., Deng Y., Ang T. W., Reed G. T.: Optical fibre sensor for monitoring flow and resin curing in composites manufacturing. Composites Part A: Applied Science and Manufacturing, 37, 934-938 (2006).

DOI: $10.1016 /$ j.compositesa.2005.03.003

[44] Li C., Cao M., Wang R., Wang Z., Qiao Y., Wan L., Tian Q., Liu H., Zhang D., Liang T., Tang C.: Fiber-optic composite cure sensor: monitoring the curing process of composite material based on intensity modulation. Composites Science and Technology, 63, 1749-1758 (2003). DOI: 10.1016/S0266-3538(03)00118-0

[45] Gupta N., Sundaram R.: Fiber optic sensors for monitoring flow in vacuum enhanced resin infusion technology (VERITy) process. Composites Part A: Applied Science and Manufacturing, 40, 1065-1070 (2009). DOI: 10.1016/j.compositesa.2009.04.022

[46] Buggy S. J., Chehura E., James S. W., Tatam R. P.: Optical fibre grating refractometers for resin cure monitoring. Journal of Optics A: Pure and Applied Optics, 9, S60-S65 (2007).

DOI: $10.1088 / 1464-4258 / 9 / 6 / \mathrm{S} 09$

[47] Fawcett A. H.: Polymer spectroscopy. Wiley, Chichester (1996).

[48] Wang L., Pandita S., Machavaram V. R., Malik S., Harris D., Fernando G. F.: Characterisation of the cross-linking process in an E-glass fibre/epoxy composite using evanescent wave spectroscopy. Composites Science and Technology, 69, 2069-2074 (2009). DOI: 10.1016/j.compscitech.2008.11.001

[49] Mahendran R. S., Wang L., Machavaram V. R., Pandita S. D., Chen R., Kukureka S. N., Fernando G. F.: Fiber-optic sensor design for chemical process and environmental monitoring. Optics and Lasers in Engineering, 47, 1069-1076 (2009). DOI: 10.1016/j.optlaseng.2009.05.013

[50] Dunkers J. P., Lenhart J. L., Kueh S. R., van Zanten J. H., Advani S. G., Parnas R. S.: Fiber optic flow and cure sensing for liquid composite molding. Optics and Lasers in Engineering, 35, 91-104 (2001). DOI: $10.1016 / \mathrm{S} 0143-8166(00) 00110-\mathrm{X}$
[51] Wood K. H., Brown T. L., Wu M. C., Gause C. B.: Fiber optic sensors for cure/health monitoring of composite materials. NASA Langley Research Center, Hampton (2004).

[52] Anne M. L., Le Gal La Salle E., Bureau B., Tristant J., Brochot F., Boussard-Plédel C., Ma H. L., Zhang X. H., Adam J. L.: Polymerisation of an industrial resin monitored by infrared fiber evanescent wave spectroscopy. Sensors and Actuators B: Chemical, 137, 687-691 (2009). DOI: $10.1016 /$ j.snb.2009.01.069

[53] Cruz J. C., Osswald T. A.: Monitoring epoxy and unsaturated polyester reactions under pressure - Reaction rates and mechanical properties. Polymer Engineering and Science, 49, 2099-2108 (2009).

DOI: $10.1002 /$ pen. 21448

[54] Childs P. R. N: Practical temperature measurement. Butterworth-Heinemann, Oxford (2001).

[55] Hsiao K-T., Little R., Restrepo O., Minaie B.: A study of direct cure kinetics characterization during liquid composite molding. Composites Part A: Applied Science and Manufacturing, 37, 925-933 (2006). DOI: 10.1016/j.compositesa.2005.01.019

[56] Tuncol G., Danisman M., Kaynar A., Sozer E. M.: Constraints on monitoring resin flow in the resin transfer molding (RTM) process by using thermocouple sensors. Composites Part A: Applied Science and Manufacturing, 38, 1363-1386 (2007).

DOI: 10.1016/j.compositesa.2006.10.009

[57] Marin E., Robert L., Triollet S., Ouerdane Y.: Liquid resin infusion process monitoring with superimposed fibre Bragg grating sensor. Polymer Testing, 31, 10451052 (2012).

DOI: 10.1016/j.polymertesting.2012.07.018

[58] Yoon H-J., Costantini D. M., Limberger H. G., Salathé R. P., Kim C-G., Michaud V.: In situ strain and temperature monitoring of adaptive composite materials. Journal of Intelligent Material Systems and Structures, 17, 1059-1067 (2006). DOI: $10.1177 / 1045389 X 06064889$

[59] Cuevas E., Garcia C., Hernandez S., Venegas P., Gomez T., Canada M.: Non destructive testing for non-cured composites: Air coupled ultrasounds and thermography. in 'Proceedings of the $5^{\text {th }}$ International Symposium on NDT in Aerospace, Singapore' p.13 (2013).

[60] Di Fratta C., Klunker F., Ermanni P.: A methodology for flow-front estimation in LCM processes based on pressure sensors. Composites Part A: Applied Science and Manufacturing, 47, 1-11 (2013). DOI: $10.1016 /$ j.compositesa.2012.11.008

[61] Govignon Q., Bickerton S., Kelly P. A.: Experimental investigation into the post-filling stage of the resin infusion process. Journal of Composite Materials, 47, 1479-1492 (2013). DOI: $10.1177 / 0021998312448500$ 
[62] Xin C., Gu Y., Li M., Li Y., Zhang Z.: Online monitoring and analysis of resin pressure inside composite laminate during zero-bleeding autoclave process. Polymer Composites, 32, 314-323 (2011). DOI: $10.1002 /$ pc. 21048

[63] Simacek P., Eksik Ö., Heider D., Gillespie J. W., Advani S.: Experimental validation of post-filling flow in vacuum assisted resin transfer molding processes. Composites Part A: Applied Science and Manufacturing, 43, 370-380 (2012). DOI: $10.1016 /$ j.compositesa.2011.10.002

[64] Kobayashi S., Tanaka A., Morimoto T.: Analytical prediction of resin impregnation behavior during processing of unidirectional fiber reinforced thermoplastic composites considering pressure fluctuation. Advanced Composite Materials, 21, 425-432 (2012). DOI: $10.1080 / 09243046.2012 .740773$

[65] Elhajjar R.: Smart composites - Mechanics and design. CRC Press, Boca Raton (2013).

[66] Zwaag S.: Self-healing materials: An alternative approach to 20 centuries of materials science. Springer Science+Business Media B.V., Dordrecht (2008).

[67] Angelidis N., Wei C. Y., Irving P. E.: The electrical resistance response of continuous carbon fibre composite laminates to mechanical strain. Composites Part A: Applied Science and Manufacturing, 35, 11351147 (2004). DOI: 10.1016/j.compositesa.2004.03.020

[68] Shen L., Li J., Liaw B. M., Delale F., Chung J. H.: Modeling and analysis of the electrical resistance measurement of carbon fiber polymer-matrix composites. Composites Science and Technology, 67, 2513-2520 (2007). DOI: 10.1016/j.compscitech.2006.12.020

[69] Todoroki A., Omagari K., Shimamura Y., Kobayashi H.: Matrix crack detection of CFRP using electrical resistance change with integrated surface probes. Composites Science and Technology, 66, 1539-1545 (2006). DOI: 10.1016/j.compscitech.2005.11.029

[70] Bakhshi M., Horoschenkoff A.: Use of carbon fiber sensors to determine the resin flow. in 'Proceedings of the $19^{\text {th }}$ ICCM Conference. Montreal, Canada', 76067613 (2013).

[71] Obaid A. A., Yarlagadda S., Yoon M. K., Hager N. E., Domszy R. C.: A time-domain reflectometry method for automated measurement of crack propagation in composites during mode I DCB testing. Journal of Composite Materials, 40, 2047-2066 (2006).

DOI: $10.1177 / 0021998306061309$
[72] Pandey G., Wolters M., Thostenson E. T., Heider D.: Localized functionally modified glass fibers with carbon nanotube networks for crack sensing in composites using time domain reflectometry. Carbon, 50, 3816-3825 (2012).

DOI: $10.1016 /$ j.carbon.2012.04.008

[73] Todoroki A., Kurokawa H., Mizutani Y., Matsuzaki R., Yasuoka T.: Self-sensing time domain reflectometry method for damage monitoring of a CFRP plate using a narrow-strip transmission line. Composites Part B: Engineering, 58, 59-65 (2014).

DOI: 10.1016/j.compositesb.2013.10.047

[74] Qin F. X., Peng H. X.: Macro-composites containing ferromagnetic microwires for structural health monitoring. Nano Communication Networks, 1, 126-130 (2010). DOI: $10.1016 /$ j.nancom.2010.08.001

[75] Phan M. H., Peng H. X., Yu S. C., Wisnom M. R.: Large enhancement of GMI effect in polymer composites containing co-based ferromagnetic microwires. Journal of Magnetism and Magnetic Materials, 316, 253-256 (2007). DOI: $10.1016 / \mathrm{j} . j \mathrm{mmm} .2007 .02 .112$

[76] Qin F. X., Brosseau C., Peng H. X., Wang H., Sun J.: In situ microwave characterization of microwire composites with external magnetic field. Applied Physics Letters, 100, 192903/1-192903/4 (2012). DOI: $10.1063 / 1.4712126$

[77] Rau M., Iftemie A., Baltag O., Costandache D.: The study of the electromagnetic shielding properties of a textile material with amorphous microwire. Advances in Electrical and Computer Engineering, 11, 17-22 (2011). DOI: 10.4316/AECE.2011.01003

[78] Qin F., Peng H-X.: Ferromagnetic microwires enabled multifunctional composite materials. Progress in Materials Science, 58, 183-259 (2013).

DOI: $10.1016 /$ j.pmatsci.2012.06.001

[79] Leng J., Du S.: Shape-memory polymers and multifunctional composites. CRC Press, Boca Raton (2010).

[80] Karbhari V. M.: Non-destructive evaluation (NDE) of polymer matrix composites. Woodhead, Cambridge (2013).

[81] Cai J., Qiu L., Yuan S., Shi L., Liu P., Liang D., Shi L.: Structural health monitoring for composite materials. in 'Composites and their applications' (ed.: Hu N.) Intech, Rijeka (2012). DOI: $10.5772 / 48215$ 